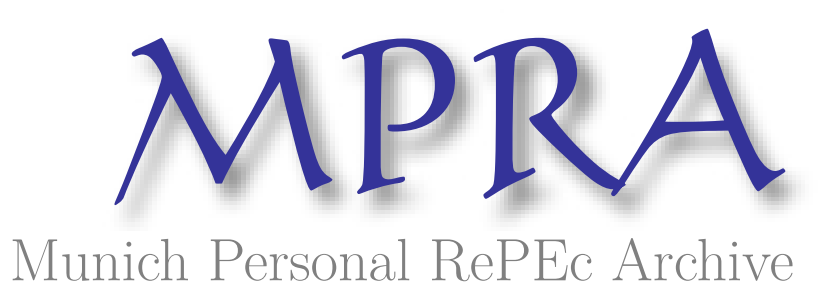

\title{
Asymmetric Price Adjustments in Airlines
}

Escobari, Diego

The University of Texas - Pan American

21 October 2012

Online at https://mpra.ub.uni-muenchen.de/42115/

MPRA Paper No. 42115, posted 22 Oct 2012 07:17 UTC 


\title{
Asymmetric Price Adjustments in Airlines*
}

\author{
Diego Escobari ${ }^{\dagger}$
}

October 21, 2012

\begin{abstract}
This paper uses a unique daily time series data set to investigate the asymmetric response of airline prices to capacity costs driven by demand fluctuations. We use a Markov regime-switching model with time-varying transition probabilities to capture the time variation in the response. The results show strong evidence of asymmetric price adjustments: positive cost shifts have a large positive effect, while negative cost shifts have no effect. The asymmetry is also explained by summer travel, but not by the size of cost shifts. The findings show the importance of consumer heterogeneity and capacity constraints as a source of asymmetric responses.
\end{abstract}

Keywords: Asymmetric pricing, Airlines, Regime switching, Capacity costs

JEL Classifications: C22, L93

${ }^{*}$ This paper benefited from comments by Jihui Chen, Damian Damianov, Walter Enders, Matt Holt, Paan Jindapon, Marie Mora, Timothy Richards, Harris Schlesinger, Danilo Trupkin and seminar participants at The University of Alabama, The University of Texas - Pan American, and the International Industrial Organization Conference in Boston. Stephanie C. Reynolds provided outstanding assistance with the data.

${ }^{\dagger}$ Department of Economics \& Finance, The University of Texas - Pan American, Edinburg, TX 78539, Phone: (956) 665-3366, Fax: (956) 665-5020, Email: escobarida@utpa.edu, URL: http://faculty.utpa.edu/escobarida 


\section{Introduction}

There is a large empirical literature showing evidence that prices respond more quickly to cost increases than to cost decreases. Peltzman (2000) shows that this phenomenon, also known as asymmetric pricing or rockets and feathers, exists in a large number of markets. Asymmetric pricing studies include, for example, Enders and Granger (1998) on the term structure of interest rates, Goodwin and Holt (1999) in the U.S. beef industry, Toolsema and Jacobs (2007) on mortgage rates, Müller and Ray (2007) on disaggregate product-level scanner data, and Zachmann and von Hirschhausen (2008) on wholesale electricity prices. The favorite place to study asymmetric pricing is retail gasoline markets, where retail and wholesale prices are readily observable by researchers. Two highly cited studies in gasoline markets are Borenstein et al. (1997), who find asymmetry from crude prices to retail prices in the U.S., and Bachmeier and Griffin (2003) who find no evidence of asymmetry. ${ }^{1}$

The main goal in this paper is to extend the existing literature by testing for the existence of asymmetric pricing in airlines. In addition, we investigate whether the asymmetric response can be characterized by specific sources of asymmetries. Despite the vast empirical literature on airline pricing, no previous study has focused on the existence of asymmetric pricing in airline markets. Most of the papers in airlines use data from the Bureau of Transportation Statistics (e.g., Borenstein and Rose (1994), Hayes and Ross (1998), and Gerardi and Shapiro (2009)), which are too aggregate to be used for asymmetric pricing. More appropriate data would need to follow day-by-day pricing decisions, such as the posted prices data used in Stavins (2001), McAfee and te Velde (2007), Bilotkach and Rupp (2011), or in Gaggero and Piga (2011). In this paper we take advantage of a unique time series daily data set, similar in construction to Alderighi et al. (2012), Escobari (2009) and Escobari (2012), that has information not only on posted prices, but on inventories of seats. An additional benefit from our data set is that it spans for 128 different departure dates keeping the same flight-numbers (e.g., American Airlines flight 1419 from St. Louis (STL) to Las Vegas (LAS)), which allows price and inventory comparisons over time.

While no research has specifically addressed asymmetries in airline price, there have been related papers that can explain price adjustments by airlines. Busse (2002) examines

\footnotetext{
${ }^{1}$ For a survey of the literature see Meyer and von Cramon-Taubadel (2004).
} 
how an airline's financial situation affects its decision to lower its price. Athey et al. (2004) present a model in which firms receive a privately observed cost shock each period and prices are strictly increasing in its cost level. Staiger and Wolak (1992) suggest that in periods of low demand, firms that have excess capacity have incentives to cut prices. In a context with uncertain demand and costly capacity, Prescott (1975) and Dana (1999) predict higher prices as a response to higher demand realizations.

Unlike other industries where observed input prices drive output prices, in airlines the main cost-based source of price dispersion within the same flight depends on the optimal peak-load pricing strategy. Borenstein and Rose (1994, p.666) explain that this cost-based price variation among passengers on the same flight or on the same flight-number over different departure dates depends on the perceived probability that demand will exceed capacity. Holding capacity fixed over flights with the same flight-number, we proxy for this cost-based source using realized demand - seats already sold. The intuition is simple, keeping the number of days to departure fixed, a larger realized demand means that there are fewer available seats, which in turn translates into a larger shadow cost of capacity for the next available seat that the airline needs to price. Notice that this is consistent with dynamic pricing in airlines, where the sellers dynamically adjust prices as the departure date nears. The key idea in dynamic pricing is that the airline will set higher prices if realized demand is larger than expected, while lower prices will be set if demand is falling short (see, e.g., Escobari (2012)). Then, the current inventory captures the cost-based price variation on the same flight (as in dynamic pricing) and on the same flight-number over different departure dates (as in the current paper).

To characterize the time variation in the response of prices to costs we use a first-order Markov-switching process as in Hamilton (1989) for the fixed transition probabilities and as in Filardo (1994) for the time-varying transition probabilities following the methodology proposed in Lo and Piger (2005). After testing for the existence of any asymmetry in the response, we examine whether the time variation of the response can be explained by specific sources of asymmetries. In particular, the paper considers four sources of asymmetries: (i) to test for asymmetric pricing we focus on the direction of the cost shift (positive vs. negative), (ii) the size of the cost shift, (iii) asymmetry related to the specific departure days (weekdays vs. holidays and weekends), and (iv) asymmetry related to the sales season 
(summer vs. fall). The time-varying transition probabilities characterizing the regime-shift are modeled as a function of state variables that describe each of these four sources of asymmetries. The benefit of this approach is that it does not force the time variation in the coefficients to correspond to a particular asymmetry and that various manifestations of asymmetries can be modeled jointly, which is helpful when sources of asymmetries are correlated.

The results show strong support for an asymmetric response, with the time variation in the response switching between periods of 'high' and period of 'low' response. Furthermore, there is strong statistical evidence that two particular sources of asymmetries explain the time variation between regimes. Positive demand shifts have a positive effect on prices, while negative demand shifts have no effect. In addition, there is evidence that cost shifts during the summer departure dates have a positive larger effect on prices than cost fluctuations once the summer travel season is over. There is little evidence that the asymmetric response is driven by the size of the cost shift or by travel during the weekends or holidays.

The organization of the paper is as follows. Section 2 explains the collection of the data, while the empirical strategy is presented in Section 3. The estimation results are presented in Section 4, followed by Section 5 that discusses various theoretical models to explain the findings. Section 6 concludes.

\section{Data}

The data set was collected during 126 consecutive days (18 weeks) between Monday June 1 and Sunday October 4, 2009 from the online travel agency Expedia.com. The data collection is initially similar to Stavins (2001), but with two important improvements. First, following Escobari (2009) and Escobari (2012), it has information on seat inventories at each price, obtained from the seat availability map where the available preferred or prime seats are counted as available seats. Second, it spans over a large number of departure dates to allow observing fluctuations in demand realizations (measured via inventories). To control for the effect of days to departure, all fares and inventory levels were collected at eight days prior to the corresponding departure date. Therefore, the actual departure dates occur between Tuesday June 9 and Monday October 12, 2009. 
To make price and costs comparable over time we follow Borenstein and Rose (1994, p.666), who explain the existence of cost-based price variation among passengers on the same flight-number over different departure dates. Hence, the collection keeps track of 32 different flight-numbers (e.g., American Airlines flight 1419 from St. Louis (STL) to Las Vegas (LAS)), where each flight-number is offered every day with the same aircraft size. $^{2}$ Each flight-number belongs to one of 18 different segments, where a segment is defined as a pair of departing and destination airports. We follow the same strategy as Escobari (2009) and Escobari (2012) to control for various sources of price dispersion in the industry. Each recorded fare corresponds to the least expensive economy-class, one-way ticket in a non-stop flight. By choosing the least expensive available fare, we control for the existence of more expensive refundable tickets. Focusing on economy class tickets controls for price differentials associated with different fare classes. Moreover, selecting one-way flights is important to control for price differentials associated with round-trip tickets, such as minimum- and maximum-stay, and Saturday-night-stayover restrictions. Choosing nonstop flights controls for price variation related to more sophisticated itineraries that may include open jaws, connecting flights and different combination of segments.

While focusing on one-way non-stop tickets help control for various sources of price dispersion and help to define a single inventory at each price, the inventory of seats is also sold as part of round-trips and longer itineraries. Even if one-way tickets are a small fraction of overall tickets sold, this should not affect the pricing equation that we will estimate as long as the carrier adjusts the observed one-way price based on the current inventory. Moreover, focusing on one-way non-stop tickets may seem restrictive when trying to generalize the results, for example, to round-trip tickets. However, this is not different than the standard assumption in papers that use data from the Bureau of Transportation Statistics, where the round-trip price is calculated as two times the one-way price. ${ }^{3}$

\section{[Insert Figure 1 here.]}

\footnotetext{
${ }^{2}$ The detail of the flights in the sample appears in the Appendix. While it would be interesting to see how between-flight heterogeneity plays a role, in this paper we follow most of the literature on asymmetric pricing (e.g., Borenstein et al. (1997), Enders and Granger (1998), Bachmeier and Griffin (2003), Müller and Ray (2007), and Toolsema and Jacobs (2007)) and focus on the time-series dimension.

${ }^{3}$ See, for example, Borenstein and Rose (1994, p. 677), and Gerardi and Shapiro (2009, p. 5).
} 
Our measure of costs is captured by relative inventory levels, defined as the ratio of the number of seats sold to total number of seats in the aircraft. Hence, it will be zero if the plane is empty and one if it is full. Figure 1 shows the average relative inventory levels (across the 32 flights in the sample) for different departure dates. The shading represents the flights scheduled to depart during weekends or during a holiday. ${ }^{4}$ There are two main things worth noting in this figure. First, demand at eight days to departure appears to have a pattern that repeats itself every week, with higher costs during the weekends and lower on Tuesdays. Second, it appears that costs are lower once the summer is over, where the difference in costs between weekends and weekdays becomes greater. One of the goals in this paper is to specifically test whether this apparently different demand (cost) behavior acts as source of asymmetry in the response of prices to costs.

\section{Empirical Strategy}

The empirical strategy to investigate how prices respond to costs is similar to Lo and Piger (2005). ${ }^{5}$ The first step is to decompose the price, $\mathrm{PRICE}_{t}$, into two unobserved additive components: a permanent component, $\operatorname{PRICE}_{t}^{P}$, and a transitory component, $\operatorname{PrICE}_{t}^{T}$. That is:

$$
\mathrm{PRICE}_{t}=\mathrm{PRICE}_{t}^{P}+\mathrm{PRICE}_{t}^{T}
$$

The permanent component is specified with the following random walk:

$$
\operatorname{PRICE}_{t}^{P}=\mu+\operatorname{PRICE}_{t-1}^{P}+\nu_{t}
$$

where we assume that the innovation $\nu_{t}$ is a normally distributed i.i.d. random variable. The forecast function of Equation 2 is linear with constant slope $\mu$ and the level changes with the realizations of $\nu_{t} \cdot{ }^{6}$ We expect this formulation of the permanent component to capture structural breaks in the pricing behavior.

\footnotetext{
${ }^{4}$ The official holiday dates during the sample period are Friday July 3 (Independence Day, observed), Monday September 7 (Labor Day), and Monday October 12 (Columbus Day).

${ }^{5}$ Lo and Piger (2005) analyze the response of output to monetary policy.

${ }^{6} \mathrm{~A}$ different formulation that modeled the drift $\mu$ as a simple random walk, allowing the level as well as the slope of the forecast function to change over time showed no low frequency shocks to the trend component. Hence, we follow the current and simpler formulation of a constant $\mu$.
} 
On the other hand, the transitory component $\mathrm{PRICE}_{t}^{T}$ is modeled as the following autoregressive process:

$$
\begin{aligned}
& \phi(L) \cdot \operatorname{PRICE}_{t}^{T}=\gamma_{0}(L) \cdot \operatorname{CosT}_{t}+\gamma_{1}(L) \cdot \operatorname{CosT}_{t} \cdot S_{t}+\varepsilon_{t}, \\
& \phi(L)=\sum_{k=0}^{K} \phi_{k} \cdot L^{k} ; \quad \phi_{0}=1 ; \quad \gamma_{i}(L)=\sum_{j=0}^{J} \gamma_{j, i} \cdot L^{j},
\end{aligned}
$$

where $\operatorname{Cost}_{t}$ is proxied by the realized demand. The idea behind this proxy is that the main cost-based source of price dispersion within the same flight depends on the optimal peak-load pricing strategy. Borenstein and Rose (1994, p.666) explain that this cost-based price variation among passengers on the same flight or on the same flight-number over different departure dates depends on the perceived probability that demand will exceed capacity. Holding capacity and the number of days prior to departure fixed (as we do in the sample), a higher realized demand means a larger shadow cost of capacity because there are fewer empty seats that the airline can sell. A seat sold today means a forgone sale to a potential passenger that may arrive closer to departure.

$S_{t}$ in Equations 3 and 4 is an indicator variable that takes the values 0 and 1 to capture the regime switches in the response of $\mathrm{PRICE}_{t}^{T}$ to $\mathrm{COST}_{t}$. This formulation is consistent with the theoretical model of price posting in Deneckere and Peck (2012), where the price responds to realized demand. This means that $\operatorname{CosT}_{t}$ can be treated as predetermined. $\phi(L)$ is a polynomial in the lag operator with all its roots lying outside the unit circle and the innovation $\varepsilon_{t}$ is a normally distributed i.i.d. random variable. This specification captures how cost fluctuations only affect the transitory component of prices and has no long-run effects on prices.

The response of the transitory component of prices to realized demand is allowed to change over time between two regimes. The regimes will be indexed by the indicator variable $S_{t}$, which is unobserved by the econometrician and has to be filtered from the data. To make the problem tractable, the estimation procedure assumes that the transition between different response regimes is governed by a first-order Markov process as in Hamilton 
(1989):

$$
\begin{aligned}
P\left(S_{t}=0 \mid S_{t-1}=0\right) & =\frac{\exp \left(c_{0}\right)}{\left(1+\exp \left(c_{0}\right)\right)} \\
P\left(S_{t}=1 \mid S_{t-1}=0\right) & =1-P\left(S_{t}=0 \mid S_{t-1}=0\right) \\
P\left(S_{t}=1 \mid S_{t-1}=1\right) & =\frac{\exp \left(c_{1}\right)}{\left(1+\exp \left(c_{1}\right)\right)} \\
P\left(S_{t}=0 \mid S_{t-1}=1\right) & =1-P\left(S_{t}=1 \mid S_{t-1}=1\right)
\end{aligned}
$$

Equations 5 consider the simple case of time invariant, or fixed transition probabilities (FTP). With FTP we will be able to capture the timing of the shifts in the response of the transitory component of prices to realized demand. However, to make the problem more interesting we will modify Equations 5 to have a time-varying transition probability (TVTP) specification as in Filardo (1994) to allow for the regime-switching process to change over time and be a function of a $q \times 1$ vector of state variables $z_{t}=\left(z_{1 t}, z_{2 t}, \ldots, z_{q t}\right)^{\prime}$ :

$$
\begin{aligned}
& P\left(S_{t}=0 \mid S_{t-1}=0\right)=\frac{\exp \left(c_{0}+z_{t}^{\prime} \cdot a_{0}\right)}{\left(1+\exp \left(c_{0}+z_{t}^{\prime} \cdot a_{0}\right)\right)} \\
& P\left(S_{t}=1 \mid S_{t-1}=1\right)=\frac{\exp \left(c_{1}+z_{t}^{\prime} \cdot a_{1}\right)}{\left(1+\exp \left(c_{1}+z_{t}^{\prime} \cdot a_{1}\right)\right)}
\end{aligned}
$$

We will choose the vector of state variables $z_{t}$ to address four different asymmetries. In particular, $z_{t}$ will include different sets of dummy variables to capture asymmetries with respect to the sign of the cost shift, the size of the cost shift, the effect of weekends and holidays, and the effect of summer travel. In addition, the testing procedure allows us to identify the effect of combinations of asymmetries (e.g., summer travel and the sign of cost shifts during the summer). $a_{0}$ and $a_{1}$ in Equation 6 are the $q \times 1$ vectors of coefficients $\left(a_{01}, a_{02}, \ldots, a_{0 q}\right)^{\prime}$ and $\left(a_{11}, a_{12}, \ldots, a_{1 q}\right)^{\prime}$ associated with $z_{t}$ at each state. $J$ lags of each of the dummy variables will be included in $z_{t}$ to be able characterize the existing conditions at the time carriers set fares.

The state dummy variable that captures the asymmetry related to the direction of the cost shift will be $\operatorname{SigN}_{t}$. It takes the value of zero if the cost shift at time $t$ is negative and will equal to one if the cost shift is positive. For the size of the cost shift, the state dummy variable $\mathrm{SizE}_{t}$ takes the value of zero if the cost shift at time $t$ is within one standard deviation of its mean, one otherwise. $\mathrm{WKND}_{t}$ is the state dummy variable equal to one if the departure date occurs during the weekend (i.e., Saturday and Sunday, not including 
Friday) or during a holiday, zero otherwise. Finally, $\mathrm{Sum}_{t}$ is the state dummy variable that characterizes summer departure dates, being equal to one if the departure date is during the summer departure dates, zero otherwise.

\section{Results}

To estimate the model described in the previous section, we will use the logarithm of the average one-way nonstop fare across the 32 flight-numbers for the $\mathrm{PRICE}_{t}$ variable. In addition, for $\mathrm{CosT}_{t}$, following Lo and Piger (2005), we will use the deviations from the difference in the logarithm of the average realized demand across the 32 flight-numbers. To be able to use maximum likelihood, we apply the filtering and smoothing algorithm presented in Kim (1994) to obtain its Markov-switching state-space representation. An unconditional expectation of the transition equation to initiate the Kalman filter portion of the filter is not available because of the non-stationarity of the transition equation for the state-space representation of the model. Therefore the filter was initiated with guesses on which we place high variance and then to allow the effects of the initial guesses to dissipate, the likelihood function was computed only after two weeks of data. Hence, even though the data starts earlier, the output will span from Monday June 27 through Saturday October $12,2009$.

\subsection{Significance of the Regime-Switch}

We now turn to test whether the regime-switching model represents a significant progress in terms of the model fit relative to the constant response coefficients. To do this we use the testing procedure developed in Hansen (1992). The significance of the FTP model is tested against the null hypothesis of constant response coefficients, that is $\gamma_{j, 0}=\gamma_{j, 1}$ for all $j \cdot{ }^{7}$ Using the test in Hansen (1992) is important because in this type of Markov-switching models, some of the nuisance parameters are not identified under the null hypothesis. Hence, the violation of this regularity condition means that the standard likelihood ratio

\footnotetext{
${ }^{7}$ To specify the lag orders $K$ and $J$ we started estimating the fixed transition probabilities model with $K=7$ and $J=7$ and then reduced the lag order until a likelihood ratio test finds a significant value for either $\phi_{k}$ or $\gamma_{j, i}$. This procedure resulted in a lag order of $K=2$ and $J=1$, which will be the ones we employ in the rest of the paper.
} 
test for the null hypothesis has an unknown distribution. The procedure yields an upper bound of the p-value for the null hypothesis, thus it is viewed as a conservative test of the null. The results provided a likelihood ratio statistic of 2.484 with an associated upper bound for the p-value of 0.01 . This is interpreted as strong evidence favoring the regimeswitching response coefficients.

\subsection{Asymmetries in the Response}

After finding that the response of prices to costs is characterized by a regime-switching model, we now move to search for specific type of asymmetries and consider the TVTP with transition probabilities characterized by Equations 6. Within the TVTP specification, $P\left(S_{t}=1 \mid S_{t-1}=1\right)$ will be modeled as a time invariant parameter because the estimation results showed that $S_{t}=1$ during very short periods of time. Hence, there is little role for $z_{t}$ to play in explaining variation within $P\left(S_{t}=1 \mid S_{t-1}=1\right)$ and the discussion will focus on the time variation in the transition probability $P\left(S_{t}=0 \mid S_{t-1}=0\right)$.

[Insert Table 1 here.]

The first specification for $z_{t}$ does not include any dummy variables and corresponds to the FTP model where Equations 6 reduce to Equations 5. The first three columns of Table 1 contain the Schwarz Information Criterion (SIC), the Akaike Information Criterion (AIC) and the maximized value of the $\log$ of the likelihood function. The four TVTP specifications for $z_{t}$ represent the four characterizations of the asymmetries explained above, that is, $\mathrm{Sign}_{t}, \mathrm{Size}_{t}, \mathrm{WKND}_{t}$, and $\mathrm{Summ}_{t}$. To see whether positive cost shifts affect prices differently than negative cost shifts, the second characterization of $z_{t}$ presented in Table 1 includes the dummy variables capturing the direction of the cost shift, $z_{t}=$ $\left(\mathrm{SIGN}_{t}, \mathrm{SIGN}_{t-1}\right)^{\prime}$. The likelihood ratio test suggests that it can explain the asymmetric response in prices. When considering whether the size, weekend travel, or summer travel drive the regime switch, the AIC prefers the $z_{t}=\left(\mathrm{Summ}_{t}, \mathrm{SUMm}_{t-1}\right)^{\prime}$ model. Moreover, the likelihood ratio test also supports $\mathrm{SuMm}_{t}$ as a source of the asymmetric response. 


\subsection{Estimation Results}

The model specification selection described above suggests that the response of the transitory component of price to cost shifts varies between two regimes and the regime shifts can be explained by specific sources of asymmetries. The probability of a regime switch was found to depend, to minor extent on (1) whether the cost shift is positive or negative and, with slightly more evidence on (2) whether the cost shift occurs during summer travel or during the fall. For comparison purposes, the first column in Table 2 presents the maximum likelihood estimates of the simple FTP model. The results for the TVTP models for different specifications of $z_{t}$ are presented in columns 2 through 5 . While none of the TVTP specifications find a statistically significant $\sigma_{\nu}$, the positive and significant estimate of $\sigma_{\nu}$ in the FTP specification suggests the existence of a permanent shock to prices.

[Insert Table 2 here.]

The transitory component of price for the SIGN specification is presented in Figure 2, where the shaded areas correspond to the dates characterized by positive cost shifts, SIGN $_{t}$ $=1$. This figure shows some relationship between increases in $\operatorname{PRICE}_{t}^{T}$ and episodes of positive cost shifts. The sharp increase in demand on Friday, October 9 may be explained by Columbus Day holiday, celebrated the following Monday 12. Moreover, there is evidence of a positively skewed PRICE ${ }_{t}^{T}$, as the positive deviations from the permanent component PRICE $_{t}^{P}$ appear larger than the negative deviations.

[Insert Figure 2 here.]

To simulate the path of $\mathrm{PRICE}_{t+j}^{T}$ as captured by Equation 3 and the estimates of the regime-switching response coefficients, $\gamma_{0,0}, \gamma_{1,0}, \gamma_{0,1}$, and $\gamma_{1,1}$, Figures 3 and 4 provide the state-dependent impulse response functions for the SIGN and SUmm specifications, respectively. The results reported in the second (SIGN) and fifth (SUmm) columns of Table 2 show that the indicator variable $S_{t}$ divides the cost shifts in two: the ones that have a relatively large and the ones that have relatively small effect on the transitory component of prices. The cost shift $\operatorname{CosT}_{t}$ is set to be equal to 0.055 , which is its historical standard deviation and corresponds to a $5.5 \%$ change in capacity utilization-ratio of occupied seat 
to total seats. The responses are obtained under four possible realizations of the indicator variables: $S_{t}=S_{t+1}=0 ; S_{t}=0$ and $S_{t+1}=1 ; S_{t}=1$ and $S_{t+1}=0 ;$ and $S_{t}=S_{t+1}=1$, where the responses only depend on $S_{t}$ and $S_{t+1}$ because $J=0,1$. As is standard in the computation of impulse response function, we make the following additional assumptions: $\operatorname{PRICE}_{t-1}^{T}=\operatorname{PRICE}_{t-2}^{T}=0, \varepsilon_{t+j}=0, \forall j$ and $\operatorname{CosT}_{t-j}=0, j \neq 0$. We can observe the positive effect of cost shifts on the transitory component of prices from the SizE specification presented in Figure 3. The contemporaneous effect is captured by $\gamma_{0,0}+\gamma_{0,1}$ times the size of the shift. We can see that the effect of a cost shift is larger when either $S_{t}=1$ or $S_{t+1}=1$. A one standard deviation increase in costs increases contemporaneous prices by $12.2 \%$ during high response regime, that is when $S_{t}=S_{t+1}=1$, or $S_{t}=1$ and $S_{t+1}=0$. A one standard deviation increase in costs increases prices by $7.8 \%$ the next period if $S_{t}=0$ and $S_{t+1}=1$. However, when $S_{t}=S_{t+1}=0$, there is only a small contemporaneous increase of $0.8 \%$. Because of the low estimated values of both, $\phi_{1}$ and $\phi_{2}$, the responses to a cost shock die down fast. Figure 4 shows very similar results for the Summ specification.

\section{[Insert Figure 3 here.]}

[Insert Figure 4 here.]

To determine the estimates of $P\left(S_{t}=0 \mid S_{t-1}=0\right)$ and $P\left(S_{t}=1 \mid S_{t-1}=1\right)$ in the FTP model, we focus our attention on the estimated coefficients $\hat{c}_{0}$ and $\hat{c}_{1}$. The first one, $\hat{c}_{0}=2.296$, is highly significant and yields an estimate of $P\left(S_{t}=0 \mid S_{t-1}=0\right)=$ $\exp \left(\hat{c}_{0}\right) /\left(1+\exp \left(\hat{c}_{0}\right)\right)=0.909$. Therefore, if $S_{t-1}=0$ meaning that we are in the low response regime, the probability of staying in this regime is fairly high. On the other hand, if we are in a high response regime, $S_{t-1}=1$, the probability that we stay in the high response regime is $P\left(S_{t}=1 \mid S_{t-1}=1\right)=\exp \left(\hat{c}_{1}\right) /\left(1+\exp \left(\hat{c}_{1}\right)\right)=0.511$ or more appropriately 0.5 , as the estimated value for $\hat{c}_{1}=0.043$ is not statistically significant.

To determine the estimates of the transition probabilities in the SIGN specification, we look at the estimated coefficients $\hat{c}_{0}, \hat{c}_{1}, \hat{a}_{01}$ and $\hat{a}_{02}$. Let's initially consider the case in which $\operatorname{SIGN}_{t-1}=\operatorname{SigN}_{t}=0$. Then, with $\hat{c}_{0}=21.371, P\left(S_{t}=0 \mid S_{t-1}=0\right)=\exp \left(\hat{c}_{0}\right) /\left(1+\exp \left(\hat{c}_{0}\right)\right)$ $=1$. This means that if $S_{t-1}=0$ and there has not been a positive demand shift recently, we will stay in the low response regime with certainty. On the other hand, if $\mathrm{SIGN}_{t-1}=$ 
SIGN $_{t}=1$ meaning that there has been a positive demand shift recently, the estimates of $\hat{a}_{01}$ and $\hat{a}_{02}$ indicate that $P\left(S_{t}=0 \mid S_{t-1}=0\right)=\exp \left(\hat{c}_{0}+\hat{a}_{01}+\hat{a}_{02}\right) /\left(1+\exp \left(\hat{c}_{0}+\hat{a}_{01}+\hat{a}_{02}\right)\right)$ $=0.726$. Hence, the probability of shifting from a low response regime, $S_{t-1}=0$, to a high response regime, $S_{t}=1$ goes from zero when there has not been a positive cost shift recently to $P\left(S_{t}=1 \mid S_{t-1}=0\right)=1-0.726=0.274$ if there has been. This result indicates that positive cost shifts are more likely to have a larger effect on prices than negative cost shifts. Finally, the statistically non-significant $\hat{c}_{1}=-0.3268$ implies that once we are in a high response regime, the probability of staying in that regime is $P\left(S_{t}=1 \mid S_{t-1}=1\right)=$ 0.5 .

The transition probabilities for the Summ specification are easier to interpret as we are either in the summer, $\mathrm{Sum}_{t-1}=\mathrm{Sum}_{t}=1$ or in the fall, $\mathrm{Sum}_{t-1}=\mathrm{Sum}_{t}=0$. During the fall, and based on the estimated $\hat{c}_{0}=3.46$ that yields a $P\left(S_{t}=0 \mid S_{t-1}=0\right)=0.969$, if $S_{t}=0$, we will stay in the low response regime with almost certainty. During the summer, and based on the estimated $\hat{c}_{1}, \hat{a}_{01}$ and $\hat{a}_{02}$ that correspond to a $P\left(S_{t}=0 \mid S_{t-1}=0\right)$ $=0.656$, if $S_{t}=0$, we are less likely to stay in the low response regime. Consequently, the probability to change from a low response regime to a high response regime during the summer is 0.344 versus 0.03 during the fall. Finally, and as in the previous case, the probability of staying in a high response regime is 0.5 , regardless on the season.

\section{[Insert Figure 5 here.]}

\section{[Insert Figure 6 here.]}

Figures 5 and 6 visually summarize the preceding discussion by presenting the filtered probability that $S_{t}=1, P\left(S_{t}=1 \mid t\right)$, for the SIGN and the Summ specifications respectively. These ones are constructed using the TVTP model of Equations 1 through 6. In Figure 5 the shaded areas correspond to the periods in which the demand shift is positive, while the shaded area in Figure 6 illustrates the summer departure dates. The figures distinguish between the two regimes, when $P\left(S_{t}=1 \mid t\right)$ is close to zero and during very short periods of time, when it is close to one. Based on the filtered probability for both specifications, we can argue that most of the time cost shifts have a small effect on prices and only during short periods the effect is large. In addition, it is easy to see how a large number 
of the shaded areas match with periods in which the probability gets closer to one. While this is not necessarily clear for Sign, in the preferred specification SUMm it is easier to distinguish the positive probabilities during the summer with almost no activity in the transition probabilities during the fall.

\subsection{Additional Results: Combined Asymmetries}

The previous section found that two specifications of the TVTP were statistically significant, with Summ being the preferred specification. We now further explore the possibility that combined asymmetries explain the shifts in the response. The first part of Table 3 investigates the robustness of the SUmm specification by adding to the vector of state variables, one at the time, Sign, Size, and Wrnd. The idea is to test if the additional variable is significant once the effect of SUMm is accounted for. The second part of Table 3 investigates whether Sign, Size, or WKND can explain variation in the regime shift within the summer departure dates, where we have three additional specifications for the state variables $z_{t}=\left(\operatorname{Summ}_{t}, \mathrm{Summ}_{t-1}, \mathrm{SUmm}_{t} \times \mathrm{SiGN}_{t}, \mathrm{Summ}_{t-1} \times \operatorname{SigN}_{t-1}\right)^{\prime}, z_{t}$ $=\left(\operatorname{Summ}_{t}, \operatorname{Summ}_{t-1}, \operatorname{Summ}_{t} \times \operatorname{SizE}_{t}, \operatorname{Summ}_{t-1} \times \operatorname{SizE}_{t-1}\right)^{\prime}$, and $z_{t}=\left(\operatorname{Summ}_{t}, \operatorname{Sum}_{t-1}\right.$, $\left.\mathrm{SUMm}_{t} \times \mathrm{WKND}_{t}, \mathrm{SUMm}_{t-1} \times \mathrm{WKND}_{t-1}\right)^{\prime}$. This in not an unconditional significance of these asymmetries, but rather we investigate for any significance of the asymmetries conditional on being in the summer.

[Insert Table 3 here.]

The results indicate that within these six additional models, the SIC and the AIC select the fourth. For this fourth model and at significance levels of $4.58 \%$ or higher, the likelihood ratio test rejects the null hypothesis of the model including only Summ. Moreover, at a significance level of $1.41 \%$ or higher, we reject the null of the FTP model. When we allow the combination of asymmetries, we conclude that the preferred specification is the one where the regime shift in the response is characterized by the difference between summer and fall travel and distinguishes between positive and negative cost shifts within the summer travel departure dates.

[Insert Figure 7 here.] 
The results from the preferred specification are summarized in two figures. Figure 7 shows the regime-dependent impulse response functions computed under the same settings as before. When $S_{t}=1$, a one standard deviation increase in $\operatorname{CosT}_{t}$ increases contemporaneous prices by $10.0 \%$ regardless of the state of the response regime in the following period, $t+1$. During a contemporaneous low response regime, $S_{t}=0$, and a high response regime next period, $S_{t+1}=1$, the cost shift has a small contemporaneous effect $(0.9 \%)$, but a large effect next period (8.8\%). Cost shifts at $t$ have almost no effect on prices during $t+1$, if $t+1$ belongs to a low response regime, $S_{t+1}=0$, being the responses $-0.9 \%$ and $-0.7 \%$ for $S_{t}=0$ and $S_{t}=1$, respectively. In sum, when either $S_{t}=1$ or $S_{t+1}=1$, the response of the transitory component of prices to cost shifts is much larger. Cost shifts at $t$ have no effect on the prices on $t+2$ and beyond.

\section{[Insert Figure 8 here.]}

Figure 8 illustrates the filtered probabilities $P\left(S_{t}=1 \mid t\right)$ to analyze the timing of the regime switches. The shaded areas correspond to positive cost shifts during the summer, $\mathrm{SIGN}_{t} \times \mathrm{Summ}_{t}=1$. This figure shows that $P\left(S_{t}=1 \mid t\right)$ is very close to one, mostly during the positive cost shifts in the summer. In addition, it is very close to zero almost throughout the fall departure dates, indicating that during this period prices respond very little to (positive or negative) demand shifts.

\section{Explaining the Asymmetry}

The easiest way to explain why prices respond asymmetrically to cost shift is to understand why inventories or realized demand serve as a proxy for costs. Airlines set capacity in advance and need to price perishable seats under a highly uncertain demand. Hence, higher demand realizations imply less available capacity, which translates into a higher opportunity cost of a sale. A higher (lower) demand realization can be interpreted as a higher (lower) opportunity cost of a seat. Therefore, several of the explanations of asymmetric pricing in other industries can also be valid for airlines. For example, Peltzman (2000) provides as one possible explanation the input price volatility, which would be consistent with a large volatility in demand realizations. Also in the asymmetric pricing literature, Noel (2008) 
explains that capacity constraints diminish the incentives to undercut prices if a firm can no longer serve the market at the new lower price. ${ }^{8}$

A second strain of literature that can motivate the existence of asymmetric price responses to capacity costs follows models that explain price dispersion as the result of price commitments, costly capacity and demand uncertainty (e.g., Prescott (1975) and Dana (1999)). In these models prices are inversely related to the probability of making a sale. Hence, when the probability of higher demand states is relatively low, moving to a higher demand state will trigger a relatively large response in prices as compared to the response in prices in lower demand states.

A third strain may come from macroeconomic models. In a generalization of Ball and Mankiw (1994), where under menu costs and an upper trend in prices - similar to higher prices in airlines closer to departure-positive shocks trigger a greater price adjustment than do negative shocks of the same size. With prices constantly going up as the departure date approaches, carriers may choose to wait until the upward trend in prices does much of the work instead of lowering prices and pay the menu cost. By contrast, a higher realization of demand induces a huge desire to increase prices. As a result, positive shocks are more likely to result in a price adjustment and positive adjustments are more likely to be larger than negative adjustments.

Finally, asymmetric price responses can also be explained by the existence of heterogeneous consumers. Notice that the asymmetry illustrated in Figure 6 can be easily explicated by differences in consumers between summer and fall travel. Moreover, consumer heterogeneity can as well explain why mid-week flights appear emptier. This is important in light of recent literature on asymmetric pricing that considers consumers' heterogeneities. Yang and Ye (2008) consider consumers with heterogeneous beliefs about costs realizations, then the existence of searchers and non-searchers drive the asymmetric price adjustment. Moreover, in the theoretical model of Cabral and Fishman (2012), consumes' willingness to search is low when they observe small price variations, while in Tappata (2009) consumers

\footnotetext{
${ }^{8}$ Some explanations given in the asymmetric pricing literature appear unlikely to work for airlines. For example, search costs in retail gasoline prices as in Lewis (2011) and as cited in Davis (2007). This is because unlike other industries, in airlines consumers can costlessly compare fares across different flights using the Internet.
} 
have heterogeneous search costs. In both of these last two models consumer's heterogeneity is key to produce asymmetric price adjustments.

\section{Conclusion}

This article uses a novel airlines daily time series data set with information on prices and realized demand intensities to test for the existence of asymmetric pricing. We find strong evidence that the coefficients measuring the response shift between a regime of no statistically significant response and a regime of positive response. When the timing of the response is allowed to change with specific sources of asymmetries, the results show strong support that the sign of the cost shifts along with the selling season can explain the regime shifts. Positive cost shifts are more likely to have a positive effect on prices than negative cost shifts. Moreover, shifts during the summer travel season were found to have a larger effect on prices. The size of the cost shift or the ex-ante known periods of high demand of holidays and weekends did not appear to explain the shifts in the response.

The results in this paper show the importance of consumers' heterogeneity, inventories, capacity constraints and the perishability of airline seats to explain asymmetric pricing. Under asymmetric pricing, higher demand states are absorbed by prices to avoid the seller to

sell out too soon. Moreover, lower demand states are absorbed by lower capacity utilizations rates rather than by lower prices.

\section{A Appendix}

[Insert Table 4 here.] 

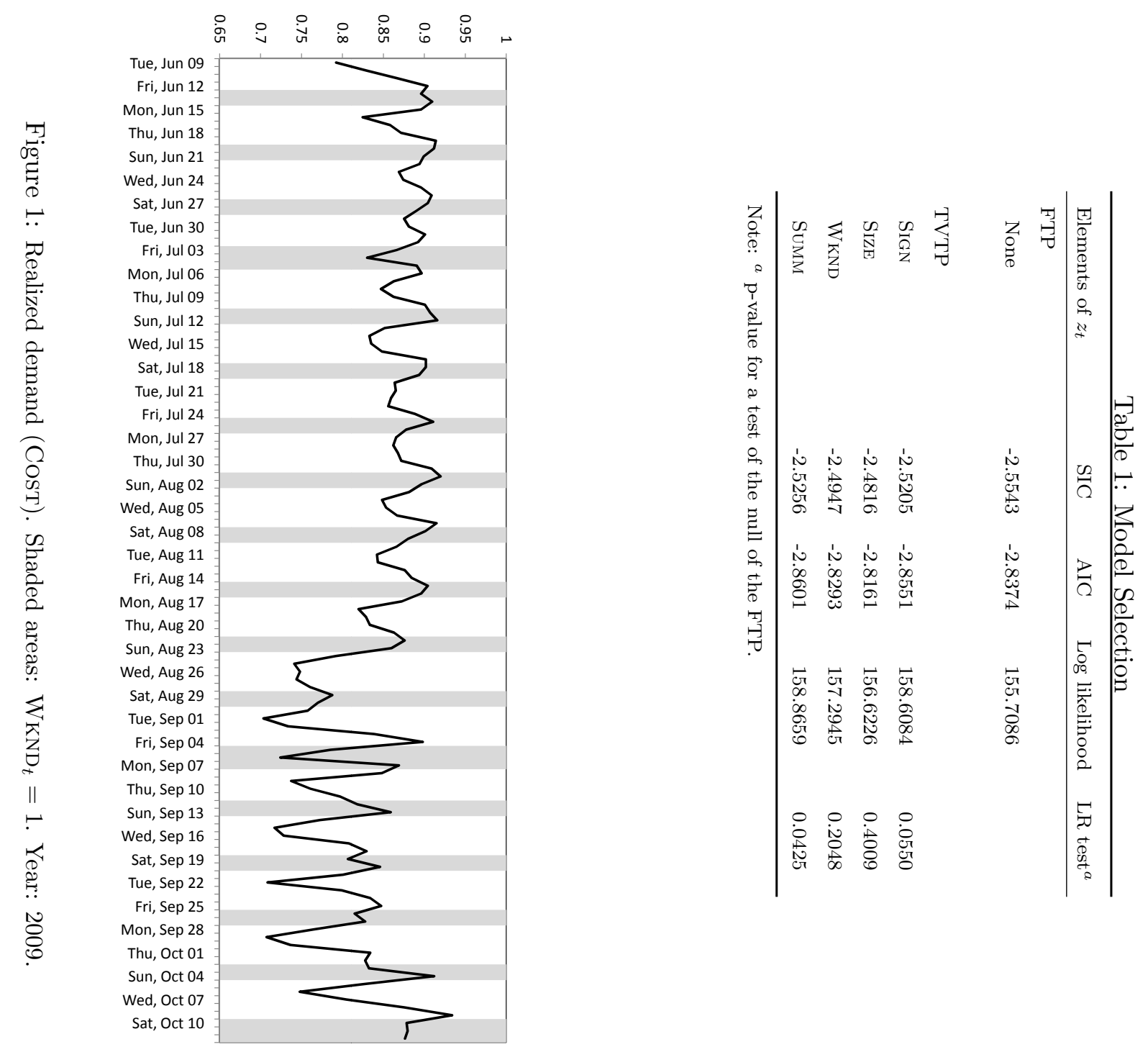
Table 2: Parameter Estimates

\begin{tabular}{|c|c|c|c|c|c|}
\hline \multirow[b]{2}{*}{$\begin{array}{l}\text { Elements of } z_{t} \text { : } \\
\text { Parameter }\end{array}$} & \multirow{2}{*}{$\begin{array}{c}\text { FTP } \\
\text { None } \\
(1)\end{array}$} & \multicolumn{4}{|c|}{ TVTP } \\
\hline & & $\begin{array}{l}\text { SigN } \\
(2)\end{array}$ & $\begin{array}{l}\text { Size } \\
(3)\end{array}$ & $\begin{array}{c}\text { WKND } \\
(4) \\
\end{array}$ & $\begin{array}{l}\text { Summ } \\
(5)\end{array}$ \\
\hline \multirow[t]{2}{*}{$\sigma_{\nu}$} & 0.0039 & 0.0061 & 0.0046 & 0.0008 & 0.0051 \\
\hline & $(0.0005)$ & $(0.0037)$ & $(0.0064)$ & $(0.0038)$ & $(0.0049)$ \\
\hline \multirow[t]{2}{*}{$\sigma_{\epsilon}$} & 0.0472 & 0.0462 & 0.0460 & 0.0478 & 0.0455 \\
\hline & $(0.0041)$ & $(0.0038)$ & $(0.0039)$ & $(0.0039)$ & $(0.0037)$ \\
\hline \multirow[t]{2}{*}{$\phi_{1}$} & 0.1995 & 0.1235 & 0.1911 & 0.2190 & 0.1856 \\
\hline & $(0.1173)$ & $(0.0935)$ & $(0.1228)$ & $(0.0137)$ & $(0.0858)$ \\
\hline \multirow[t]{2}{*}{$\phi_{2}$} & -0.0100 & -0.0038 & -0.0091 & -0.0120 & -0.0086 \\
\hline & $(0.0117)$ & $(0.0058)$ & $(0.0117)$ & $(0.0598)$ & $(0.0080)$ \\
\hline \multirow[t]{2}{*}{$\gamma_{0,0}$} & 0.0995 & 0.1518 & 0.0908 & 0.0861 & 0.0862 \\
\hline & $(0.1150)$ & $(0.0966)$ & $(0.1073)$ & $(0.0882)$ & $(0.0971)$ \\
\hline \multirow[t]{2}{*}{$\gamma_{1,0}$} & -0.1122 & -0.1390 & -0.1288 & -0.1098 & -0.1404 \\
\hline & $(0.0954)$ & $(0.0879)$ & $(0.0948)$ & $(0.0929)$ & $(0.0913)$ \\
\hline \multirow[t]{2}{*}{$\gamma_{0,1}$} & 2.4106 & 2.0317 & 2.3063 & 2.5431 & 2.2110 \\
\hline & $(0.5238)$ & $(0.5869)$ & $(0.6688)$ & $(0.4653)$ & $(0.5563)$ \\
\hline \multirow[t]{2}{*}{$\gamma_{1,1}$} & 0.8779 & 1.5148 & 0.9326 & 0.7594 & 0.8841 \\
\hline & $(0.4517)$ & $(0.6347)$ & $(0.4614)$ & $(0.4390)$ & $(0.3893)$ \\
\hline \multirow[t]{2}{*}{$c_{0}$} & 2.2963 & 21.3711 & 1.3803 & 1.7558 & 3.4565 \\
\hline & $(0.5620)$ & $\left(-^{a}\right)$ & $(0.8459)$ & $(0.5647)$ & $(1.0222)$ \\
\hline \multirow[t]{2}{*}{$c_{1}$} & 0.0434 & -0.3268 & -0.0754 & 0.1339 & 0.8511 \\
\hline & $(0.4481)$ & $(0.9417)$ & $(1.9404)$ & $(0.9612)$ & $(0.7516)$ \\
\hline \multirow[t]{2}{*}{$a_{01}$} & & -9.6909 & 1.0691 & 4.6457 & -8.0797 \\
\hline & & $(0.5538)$ & $(1.2950)$ & (1.6140) & $(1.2852)$ \\
\hline \multirow[t]{2}{*}{$a_{02}$} & & -10.7071 & 1.0616 & 19.8223 & 5.2679 \\
\hline & & $\left(-^{a}\right)$ & $(1.2449)$ & $\left(-^{a}\right)$ & $\left(-^{a}\right)$ \\
\hline Log likelihood & 155.7086 & 158.6084 & 156.6226 & 157.2945 & 158.8659 \\
\hline
\end{tabular}

Notes: ${ }^{a}$ The ML estimate appears on the boundary, violating regularity conditions. Hence, to calculate the standard errors this coefficient was held constant. 
Table 3: Model Selection: Combined Asymmetries

\begin{tabular}{lccccc}
\hline Elements of $z_{t}$ & SIC & AIC & Log likelihood & LR test & \\
\hline TVTP & & & & & \\
LR test
\end{tabular}

Note: ${ }^{a}$ p-value for a test of the null of the FTP model. ${ }^{b}$ p-value for a test of the null of the Summ model.

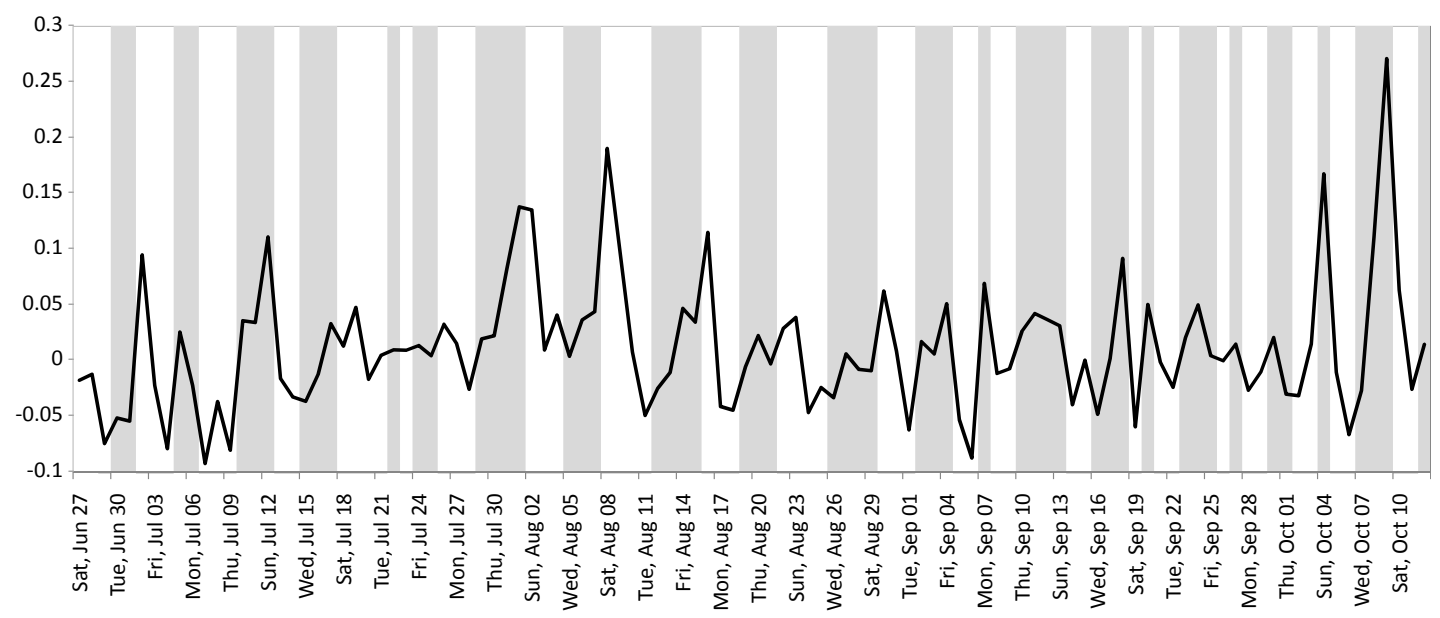

Figure 2: Estimated Transitory Component, PricE ${ }_{t}^{T}$. TVTP: Sign. Shaded areas: Sign $=1$. Year: 2009 . 
Table 4: Flights in the Sample

\begin{tabular}{|c|c|c|c|c|c|}
\hline Route & Carrier & Flights & Route & Carrier & Flights \\
\hline Atlanta (ATL) - San Jose (SJC) & Delta & 1579 & Miami (MIA) - New Orleans (MSY) & AA & 637 \\
\hline Atlanta (ATL) - Syracuse (SYR) & Delta & $5471 / 5472$ & Miami (MIA) - New Orleans (MSY) & AA & 317 \\
\hline Atlanta (ATL) - Syracuse (SYR) & Delta & 5601 & Miami (MIA) - Raleigh-Durham (RDU) & AA & 1004 \\
\hline Baltimore (BWI) - Phoenix (PHX) & US & $365 / 506$ & Miami (MIA) - Raleigh-Durham (RDU) & AA & $820 / 674$ \\
\hline Boston (BOS) - Phoenix (PHX) & US & 367 & Miami (MIA) - Raleigh-Durham (RDU) & AA & $978 / 1800$ \\
\hline Boston (BOS) - Salt Lake City (SLC) & Delta & $1261 / 1707$ & Miami (MIA) - Lambert-St. Louis (STL) & $\mathrm{AA}$ & 583 \\
\hline Charleston (CHS) - Washington-Reagan (DCA) & US & 4024 & Miami (MIA) - Lambert-St. Louis (STL) & AA & $1905 / 1811$ \\
\hline Cincinnati (CVG) - Las Vegas (LAS) & Delta & $1543 / 1551$ & Portland (PDX) - Las Vegas (LAS) & $\mathrm{AL}$ & 626 \\
\hline Dallas-Fort Worth (DFW) - New York-JFK (JFK) & Delta & 6758 & Portland (PDX) - Las Vegas (LAS) & $\mathrm{AL}$ & 622 \\
\hline Dallas-Fort Worth (DFW) - New York-JFK (JFK) & $\mathrm{AA}$ & $400 / 490$ & Portland (PDX) - Las Vegas (LAS) & $\mathrm{AL}$ & 624 \\
\hline Houston (IAH) - New York-JFK (JFK) & Delta & 6822 & Washington-Dulles (IAD) - Charleston (CHS) & $\mathrm{UN}$ & $7887 / 7983$ \\
\hline St. Louis (STL) - Las Vegas (LAS) & $\mathrm{AA}$ & 1419 & Washington-Dulles (IAD) - Charleston (CHS) & $\mathrm{UN}$ & $7337 / 7888$ \\
\hline Los Angeles (LAX) - Orlando (MCO) & AA & 244 & Washington-Dulles (IAD) - Charleston (CHS) & $\mathrm{UN}$ & $7918 / 7923$ \\
\hline Los Angeles (LAX) - Orlando (MCO) & Delta & 1430 & Washington-Dulles (IAD) - Charleston (CHS) & $\mathrm{UN}$ & $7979 / 7906$ \\
\hline Los Angeles (LAX) - Orlando (MCO) & Delta & $1480 / 1432$ & Washington-Dulles (IAD) - Salt Lake City (SLC) & Delta & $1214 / 1209$ \\
\hline Miami (MIA) - New Orleans (MSY) & $\mathrm{AA}$ & $1451 / 1329$ & Washington-Reagan (DCA) - Las Vegas (LAS) & US & $48 / 873$ \\
\hline
\end{tabular}

Note: When two flight numbers appear, the flights had the same schedule (plus/minus 15 minutes) and the aircraft size was the same. 


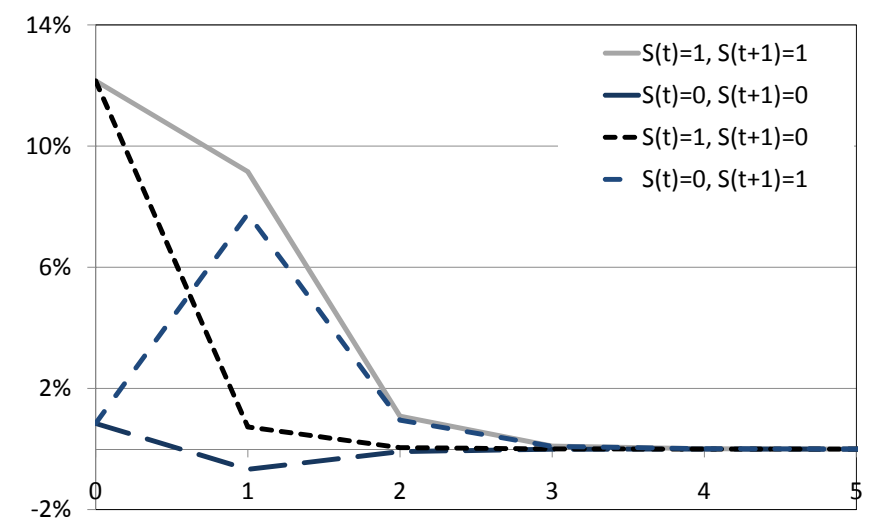

Figure 3: Impulse response function of $\mathrm{PRICE}_{t}^{T}$. TVTP: Sign.

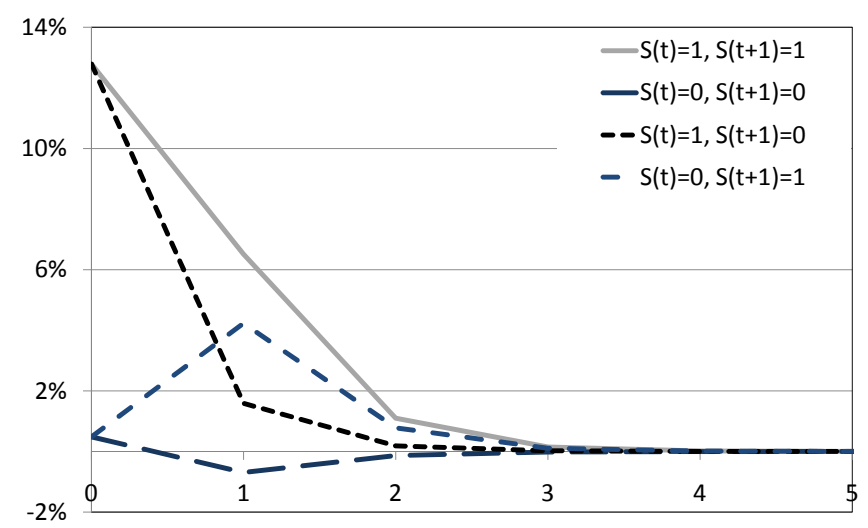

Figure 4: Impulse response function of PRICE ${ }_{t}^{T}$. TVTP: Summ. 


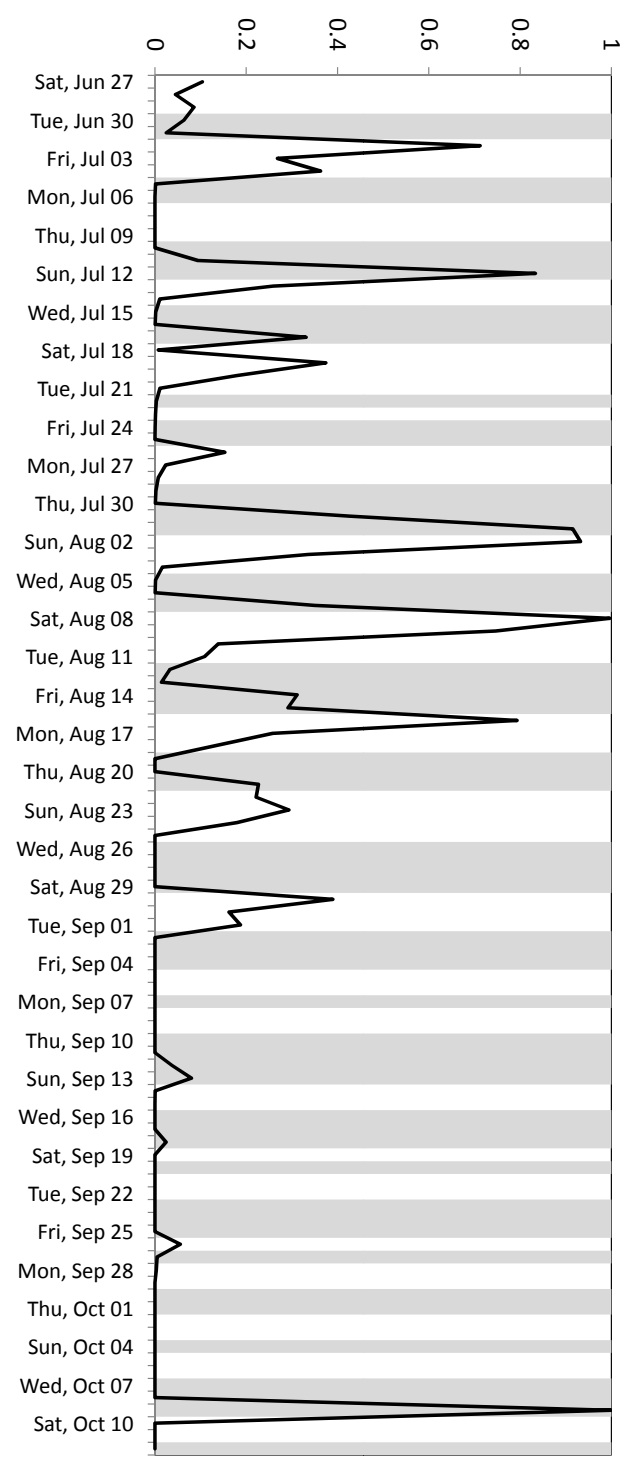



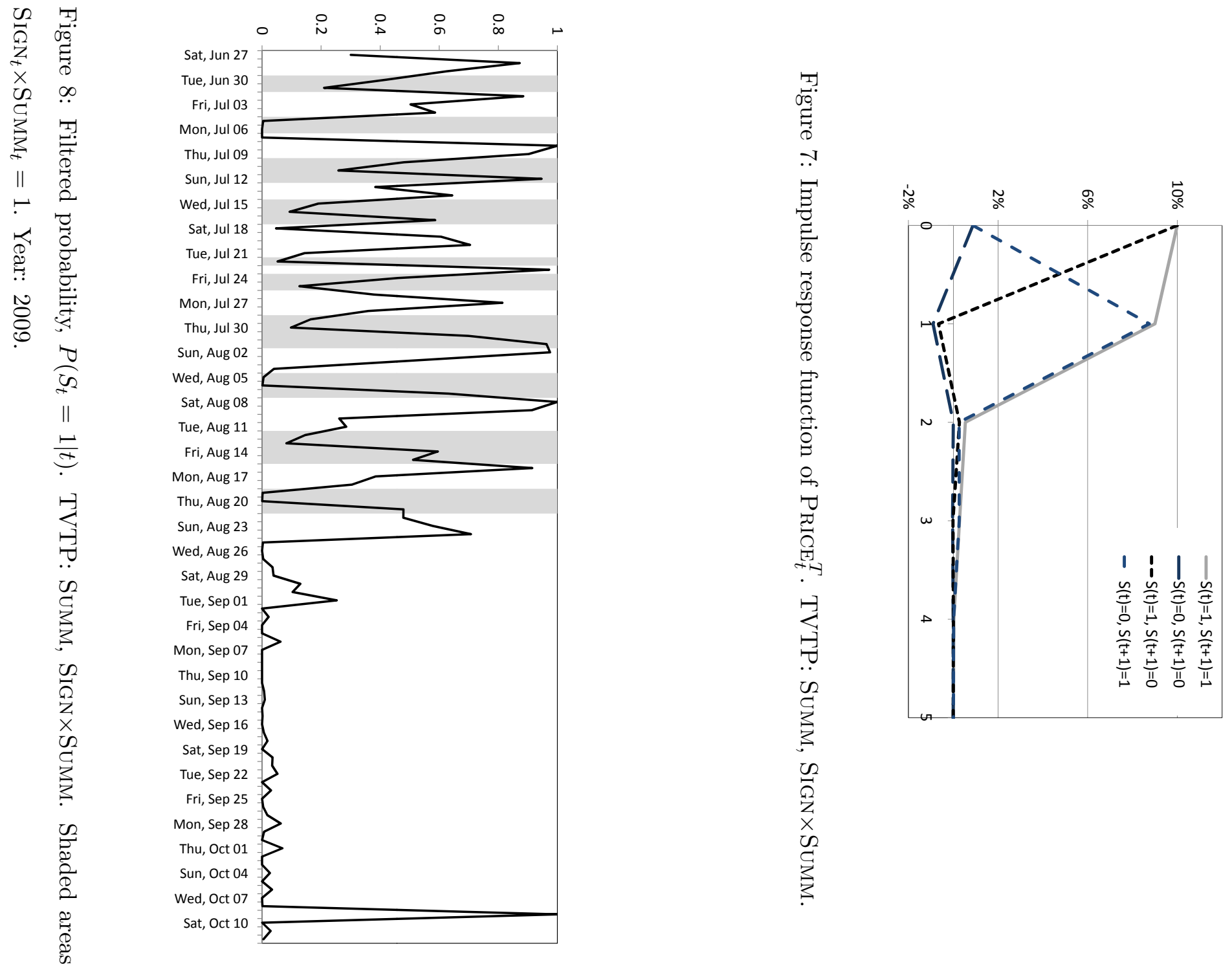


\section{References}

Alderighi, M., M. Nicolini, and C.A. Piga, 2012. Combined Effects of Load Factors and Booking Time on Fares: Insights from the Yield Management of a Low-Cost Airline. FEEM Working Paper.

Athey, S., K. Bagwell and C. Sanchirico, 2004. Collusion and price rigidity. Review of Economic Studies 71, 317-349.

Ball, L. and N.G. Mankiw, 1994. Asymmetric price-adjustment and economic fluctuations. The Economic Journal 104, 247-261.

Bachmeier, L.J. and J.M. Griffin, 2003. New evidence on asymmetric gasoline price responses. Review of Economics and Statistics 85, 772-776.

Bilotkach, V., 2006. Understanding price dispersion in the airline industry: Capacity constraints and consumer heterogeneity. In Advances in Airline Economics, Vol. 1, edited by Darin Lee. New York: Elsevier Sci.

Bilotkach, V. and N. Rupp, 2011. A guide to booking airline tickets online. mimeo. University of California, Irvine.

Borenstein, S. and N.L. Rose, 1994. Competition and price dispersion in the U.S. airline industry. Journal of Political Economy 102, 653-683.

Borenstein, S., C.A. Cameron and R. Gilbert, 1997. Do gasoline prices respond asymmetrically to crude oil price changes? Quarterly Journal of Economics 112, 305-339.

Busse, M., 2002. Firms financial condition and airline price wars. Rand Journal of Economics 33, 298-318.

Cabral, L. and A. Fishman, 2012. Business as usual: A consumer search theory of sticky prices and asymmetric price adjustment. International Journal of Industrial Organization Forthcoming.

Dana, Jr. J.D., 1999. Equilibrium price dispersion under demand uncertainty: The roles of costly capacity and market structure. Rand Journal of Economics 30, 632-660. 
Davis, M.C., 2007. The dynamics of daily retail gasoline prices. Managerial and Decision Economics 28, 713-722.

Deneckere, R. and J. Peck, 2012. Dynamic competition with random demand and costless search: A theory of price posting. Econometrica 80, 1185-1247.

Enders, W. and C.W.J. Granger, 1998. Unit-root tests and asymmetric adjustment with an example using the term structure of interest rates. Journal of Business $\&$ Economic Statistics 16, 304-311.

Escobari, D., 2009. Systematic peak-load pricing, congestion premia and demand diverting: Empirical evidence. Economics Letters 103, 59-61.

Escobari, D., 2012. Dynamic pricing, advance sales, and aggregate demand learning in airlines. Journal of Industrial Economics Forthcoming.

Escobari, D. and L. Gan, 2007. Price dispersion under costly capacity and demand uncertainty. NBER working paper 13075, Cambridge, MA.

Filardo, A.J., 1994. Business-cycle phases and their transitional dynamics. Journal of Business and Economics Statistics 12, 299-308.

Gaggero, A.A. and C.A. Piga, 2011. Airline market power and intertemporal price dispersion. Journal of Industrial Economics 59, 552-577.

Gerardi, K.S. and A.H. Shapiro, 2009. Does competition reduce price dispersion? New evidence from the airline industry. Journal of Political Economy 117, 1-37.

Goodwin, B.K. and M.T. Holt, 1999. Price transmission and asymmetric adjustment in the U.S. beef sector. American Journal of Agricultural Economics 81, 630-637.

Hamilton, J.D., 1989. A new approach to the economic analysis of nonstationary time series and the business cycle. Econometrica 57, 357-384.

Hansen, B.E., 1992. The likelihood ratio test under nonstandard conditions: Testing the Markov switching model of GNP. Journal of Applied Econometrics 7, S61-S82. 
Hayes, K.J. and L.B. Ross, 1998. Is airline price dispersion the result of careful planning or competitive forces? Review of Industrial Organization 13, 523-541.

Kim, C-J., 1994. Dynamic linear models with Markov-switching. Journal of Econometrics $60,1-22$.

Lewis, M.S., 2011. Asymmetric price adjustment and consumer search: An examination of the retail gasoline market. Journal of Economics and Management Strategy 20, 409-449.

Lo, M.C. and J. Piger, 2005. Is the response of Output to monetary policy asymmetric? Evidence from a regime-switching coefficients model. Journal of Money, Credit, and Banking 37, 865-886.

McAfee, R.P. and V. te Velde, 2007. Dynamic pricing in the airline industry. In Handbook of Economics and Information Systems, vol. 1, edited by T.J. Hendershott. New York: Elsevier Sci.

Meyer, J. and S. von Cramon-Taubadel, 2004. Asymmetric price transmission: a survey. Journal of Agricultural Economics 55, 581-611.

Müller, G. and S. Ray, 2007. Asymmetric price adjustment: evidence from weekly productlevel scanner price data. Managerial and Decision Economics 28, 723-736.

Noel, M.D., 2008. Edgeworth Price Cycles and Focal Prices: Computational Dynamic Markov Equilibria. Journal of Economics 8 Management Strategy 17, 345-377.

Peltzman, S., 2000. Prices rise faster than they fall. Journal of Political Economy 108, 466-502.

Prescott, E., 1975. Efficiency of the natural rate. Journal of Political Economy 83, 12291236.

Staiger, R.W. and F.A. Wolak, 1992. Collusive pricing with capacity constraints in the presence of demand uncertainty. Rand Journal of Economics 23, 203-220.

Stavins, J., 2001. Price discrimination in the airline market: The effect of market concentration. The Review of Economics and Statistics 83, 200-202. 
Tappata, M., 2009. Rockets and feathers: Understanding asymmetric pricing. Rand Journal of Economics 40, 673-687.

Toolsema, L.A. and J.P.A.M. Jacobs, 2007. Why do prices rise faster than they fall? with an application to mortgage rates. Managerial and Decision Economics 28, 701-712.

Yang, H. and L. Ye, 2008. Search with learning: understanding asymmetric price adjustments. Rand Journal of Economics 39, 547-564.

Zachmann, G. and C. von Hirschhausen, 2008. First evidence of asymmetric cost passthrough of EU emissions allowances: Examining wholesale electricity prices in Germany. Economics Letters 99, 465-469. 